University of Nebraska - Lincoln

DigitalCommons@University of Nebraska - Lincoln

2010

Adolescents' Occupational and Educational Aspirations and

Expectations: Links to High School Activities and Adult Educational Attainment

Sarah J. Beal

University of Nebraska-Lincoln

Lisa J. Crockett

University of Nebraska-Lincoln, ecrockett1@unl.edu

Follow this and additional works at: https://digitalcommons.unl.edu/psychfacpub

Part of the Psychiatry and Psychology Commons

Beal, Sarah J. and Crockett, Lisa J., "Adolescents' Occupational and Educational Aspirations and Expectations: Links to High School Activities and Adult Educational Attainment" (2010). Faculty Publications, Department of Psychology. 491.

https://digitalcommons.unl.edu/psychfacpub/491

This Article is brought to you for free and open access by the Psychology, Department of at DigitalCommons@University of Nebraska - Lincoln. It has been accepted for inclusion in Faculty Publications, Department of Psychology by an authorized administrator of DigitalCommons@University of Nebraska - Lincoln. 
Published in Developmental Psychology 46:1 (2010), pp. 258-265; doi: 10.1037/a0017416 Copyright @ 2010 American Psychological Association. Used by permission. "This article may not exactly replicate the final version published in the APA journal. It is not the copy of record." http://www.apa.org/pubs/journals/dev/

This research was funded by Office of Adolescent Pregnancy Programs Grant APR 000933-01 to Judith R. Vicary and National Institute on Alcohol Abuse and Alcoholism Grant 1R01AA009678-01A2 to Lisa J. Crockett. We gratefully acknowledge the contributions of the participating schools and the project staff of the Rural Adolescent Development Study and the Rural Young Adult Transitions Study. We also wish to thank Gustavo Carlo and Marcela Raffaelli for their helpful comments on an earlier version of this article.

Submitted August 26, 2008; revised June 18, 2009; accepted June 25, 2009.

\title{
Adolescents' Occupational and Educational Aspirations and Expectations: Links to High School Activities and Adult Educational Attainment
}

\author{
Sarah J. Beal and Lisa J. Crockett \\ Department of Psychology, University of Nebraska-Lincoln \\ Corresponding author - Lisa J. Crockett, Department of Psychology, \\ University of Nebraska-Lincoln, 315 Burnett Hall, Lincoln, NE 68588-0308; e-mail ecrockett1@unl.edu
}

\begin{abstract}
This longitudinal study explored adolescents' future-oriented cognitions, current activities, and later educational attainment using data from 317 adolescents ( $55 \%$ female; mean age $=14.98$ years, $S D=0.85$ ) followed into early adulthood. Aspirations and expectations regarding work and education showed modest stability from year to year. Exploration of the reciprocal relations between these cognitions and adolescents' activities supported both unidirectional and bidirectional effects, with different patterns emerging for aspirations and expectations. In multiple regression analyses, future-oriented cognitions predicted adult educational attainment; follow-up analyses indicated that the effect of adolescents' expectations was partially mediated by participation in extracurricular activities. These results suggest a potentially important influence of adolescents' future-oriented cognitions on their current behavior and future attainments.
\end{abstract}

Keywords: adolescence, educational attainment, aspirations, expectations

Adolescence is a period of exploration, when planning for the future emerges as an important developmental task (Erikson, 1968). Adolescents develop an extended future orientation in which they are able to think, dream, and plan for their futures (Blakemore \& Choudhury, 2006). They can anticipate common events, such as school completion, and estimate the ages at which they will likely experience them (Crockett \& Bingham, 2000; Nurmi, 1989, 1991). Cantor (1990) has proposed that as adolescents transition into adulthood, they become more focused on their desires and aspirations for the future and show increased selectivity in goal-directed behavior. During this period, adolescents also engage in exploratory behaviors that may aid in elaborating their sense of identity, providing information about the self that affects future plans (Eccles, Barber, Stone, \& Hunt, 2003).

Theoretical accounts posit that future-oriented cognitions change during adolescence. Gottfredson (1981) argued that, with development, adolescents' aspirations become more realistic, based on their interests, perceived abilities, and individual characteristics as well as the opportunities available to them. Nurmi (2004) suggested that adolescents' aspirations initially develop as vague representations of possible future outcomes based on societal norms and parental expectations. As adolescents gain experience, they develop more self-knowledge (Eccles et al., 2003), which should lead to further refinements in their aspirations and expectations.

Adolescents' thoughts about their future selves are important because they presumably influence choices, decisions, and activities, which in turn affect subsequent accomplishments (Nurmi, 2004). Empirical studies are sparse but provide support for the role of future-oriented cognitions in adolescents' later attainment. For example, adolescents' educational expectations predict their educational attainment (Messersmith \& Schulenberg, 2008; Ou \& Reynolds, 2008), and occupational expectations predict occupational attainment (Armstrong \& Crombie, 2000; Gottfredson, 1981). A separate literature documents the connections between adolescents' behavioral choices and their future outcomes, particularly their educational and occupational attainment (King, Meehan, Trim, \& Chassin, 2006; Troutman \& Dufur, 2007). For example, Eccles and Barber (1999) reported that participation in certain high school activities was associated with future college attendance.

Although the literature suggests that adolescents' futureoriented cognitions shape their ultimate attainments, the underlying processes through which this occurs are not well understood. Scholars have used different terminology to refer to future-oriented cognitions and their effects. Nurmi (2004) proposed that adolescents develop goals relevant to their expectations for the future, which motivate achievement. Little (2007) suggested that individuals develop "personal projects" they wish to accomplish, which motivate future attainments. Markus and Nurius (1986) proposed that individuals develop "possible selves," which motivate behaviors relevant to achieving desired future states. Despite the differences in terminology, these models all imply that future-oriented cognitions motivate behaviors related to the realization of preferred outcomes. However, the role of behaviors in linking adolescents' future-oriented cognitions and their future attainments has rarely been examined. 
Additionally, some scholars (e.g., Gottfredson, 1981; Markus \& Nurius, 1986) make a distinction between what individuals aspire to and what they expect. Gottfredson (1981) distinguished between occupational aspirations, or the realm of possible options, and expectations, the most likely outcome that an individual pursues. Similarly, Markus and Nurius (1986) identified different types of possible selves: Hoped-for selves are desired future states and motivate behaviors that increase the chances of goal attainment; feared selves are undesirable states and motivate behaviors intended to avoid those outcomes; and expected selves reflect likely outcomes and motivate behaviors that maintain this probable trajectory.

Thus, future-oriented cognitions (in different forms) are believed to shape ongoing behavior. In addition, future-oriented cognitions may be influenced by current activities, in which feedback based on behavioral performance results in an adjustment of future expectations. Oyserman and Markus (1990) reported that the expected selves of delinquents declined more than those of nondelinquents over a 3-month period, suggesting that delinquent behavior resulted in lowered expectations. Thus, it appears that future-oriented cognitions could influence adolescents' participation in behaviors and activities and that adolescents' experiences in these activities may provide feedback to the self that influences future-oriented cognitions in an ongoing, reciprocal process. However, to our knowledge, no studies have explored the possibility of reciprocal relations between future-oriented cognitions and behavior during adolescence.

Four research questions guided this exploratory study. First, do future-oriented cognitions (occupational and educational) change during adolescence? Second, do adolescents' future-oriented cognitions predict adolescents' activities, and vice versa? Third, do aspirations and expectations have distinct effects on adult educational attainment? Fourth, are the associations between adolescents' future-oriented cognitions and adult educational attainment attributable in part to their high school activities? We expected that future-oriented cognitions would change over the high school years and that cognitions and activities should show reciprocal effects. We also thought that aspirations and expectations might have distinct effects and explored whether these effects operated through adolescents' high school activities. Educational attainment was the focus because it is typically completed by early adulthood.

\section{Method}

\section{Sample}

As part of a larger longitudinal study, adolescents were recruited from a rural school district located approximately 3 hours from the nearest urban center (Crockett \& Bingham, 2000). According to census data, community residents were middle to low income and approximately $96 \%$ White; over two thirds (69\%) of adults had a high school education or less, the median household income was $\$ 14,500$, and the primary occupational categories were laborers and technical or clerical. Approximately $12 \%$ of families were below poverty level.

All students in Grades 7, 8, and 9 were invited to participate in the study. Participants in these three cohorts were surveyed annually through 12th grade and followed up in early adulthood. Over $90 \%$ of those invited participated in the first survey, and $60 \%$ of the longitudinal sample participated in the young adult follow-up. The analytic sample for the present study included 317 adolescents (55\% female) who were present at three time points: when youth were in Grades 9-11 (Time 1 [T1]; mean age $=14.98$ years, $S D=$ 0.85), 1 year later (Time 2 [T2], Grades 10-12), and 7 years later when participants were 21-27 years old (Time 3 [T3]; $M=23.11, S D=0.94)$. This sample represents $55 \%$ of the total T1 sample, due largely to sample loss between T2 and T3. Attrition analyses comparing the analytic sample with those present at $\mathrm{T} 1$ but not at the adult follow-up indicated significant differences in gender, age, grade point average (GPA), and substance use (all measured at T1). The final sample consisted of fewer male participants $(\eta=.03)$, was younger $(\eta=.01)$, and had lower levels of substance use $(\eta=.01)$ and higher GPAs $(\eta=.01)$ than the attritted sample. There were no significant differences in aspirations and expectations between analytic and attritted samples.

\section{Measures}

In adolescence ( $\mathrm{T} 1$ and $\mathrm{T} 2)$, project personnel administered questionnaires every fall during regular school hours. Information was kept confidential, and school personnel were not involved in data collection. All adolescent measures were administered at T1 and T2. Data in early adulthood (T3) were collected through mailed surveys.

Future-oriented cognitions (T1 and T2). Participants reported their occupational aspirations and expectations for "when they were older or finished school," using the following openended questions: "What kind of work would you like to do?" (occupational aspirations) and "What work do you think you will probably do?" (occupational expectations). Responses were coded with occupational prestige scores provided by the National Opinion Research Center. Scores could range from 10 (low prestige) to 100 (high prestige). Adolescents' educational expectations were measured with the question "How far do you plan to go in school?" Response options ranged from 1 (some high school) to 6 (completing a professional degree).

High school activities (T1 and T2). Positive behaviors (which adolescents should engage in for attainment) and negative behaviors (which adolescents should avoid for attainment) were measured with the Primary Prevention Awareness, Attitudes and Usage Scale (PPAAUS; Swisher, Shute, \& Bibeau, 1984). Positive behaviors included single-item measures of four kinds of activities: academic (e.g., school projects), extracurricular (e.g., clubs, band), volunteer (e.g., helping a charity), and vocational (e.g., part-time jobs). Adolescents reported their frequency of engaging in these activities, with response options ranging from 1 (never) to 6 (many times daily). Although information on test-retest reliability was not available for this study, the PPAAUS measure has been previously validated (Swisher et al., 1984). Negative activities included substance use and minor delinquency. Substance use was measured on a three-item scale (e.g., "How often have you been drunk?"; $\alpha=.67)$. Minor delinquency was measured on a 12-item scale $(\alpha=.82)$, with questions such as "How often have you broken school property on purpose?" For each scale, responses ranged from 1 (never) to 6 (almost every day or more). Items were averaged to yield total scores.

Young adult educational attainment (T3). In early adulthood, participants were asked, "How much education have 
you completed?" Responses were given on a scale of 1 (some high school) to 6 (completed a professional degree).

Control variables. Mother's education, gender, age, and GPA - variables known to predict educational attainment (Ou \& Reynolds, 2008) - were included as controls in multivariate models. Adolescents reported their mother's education on a scale of 1 (did not complete high school) to 7 (graduate or professional degree), as a proxy for socioeconomic status. Gender (female $=1$, male $=2$ ) and age in years were also reported. Academic performance (GPA) was assessed with the question "What are your marks in school?" with possible responses ranging from 1 (mostly $F^{\prime} s$ ) to 10 (mostly $A^{\prime}$ s).

\section{Results}

\section{Preliminary Analyses}

Descriptive statistics and bivariate correlations for all study variables at $\mathrm{T} 1$ and $\mathrm{T} 3$ are provided in Table 1 . The full correlation matrix is available upon request. All variables were normally distributed. Bivariate correlations indicated significant positive relations among the three future-oriented cognitions $(r \mathrm{~s}=.36-.60, p \mathrm{~s}<.01)$. All three were significantly and positively related to educational attainment $(r \mathrm{~s}=.25-.57)$. Occupational aspirations were positively related to academic activities and negatively related to vocational activities. Occupational expectations were positively related to academic and extracurricular activities and negatively related to vocational activities. Educational expectations were positively related to academic and extracurricular activities and negatively related to substance use and vocational activities. Finally, academic and extracurricular activities were positively related to educational attainment, whereas substance use, delinquency, and vocational activities were negatively related to educational attainment. $T$ tests indicated no significant gender differences in any future-oriented cognitions ( $p s>.10)$.

\section{Stability and Change in Future-Oriented Cognitions}

We explored developmental changes in future-oriented cognitions in two ways. First we examined the stability coefficients from T1 to T2. These ranged from .33 to .65 , indicating moderate stability. Second, to illuminate the types of changes adolescents' experienced, we divided the scores for each future-oriented cognition into categories. For occupational aspirations and expectations, prestige scores were split into three groups: scores from 10 to 30 (corresponding to unskilled and semiskilled manual labor), from 31 to 50 (consisting primarily of skilled labor, technical, and lower level white-collar occupations), and above 50 (professional occupations requiring higher levels of skill and training). Educational expectation scores were divided into three groups, representing "less than a college education," "some college or college degree," and "advanced degree," respectively. Frequencies for these categories at T1 and T2 are provided in Table 2. For occupational aspirations, $35.74 \%$ of adolescents changed from T1 to T2, with similar numbers of youth shifting to more prestigious and less prestigious occupations, $X^{2}(4)=34.96, p<.05$. Similarly, $37.59 \%$ of adolescents changed their occupational expectations, with equal movement toward higher and lower prestige jobs, $\chi^{2}(4)=40.10$, $p<.05$. For educational expectations, $37.83 \%$ of adolescents changed groups, with the majority moving to higher expected levels of completed education, $\chi^{2}(4)=116.59, p<.05$. Thus, for each future cognition, more than one third of the adolescents changed categories over a 1-year period.

\section{Correspondence between Aspirations and Expectations}

To examine the correspondence between occupational aspirations and expectations, we conducted a cross-tabulation at T1 using the categories just described. For $79 \%$ of the adolescents, aspirations and expectations fell into the same category $(4 \%$ had aspirations and expectations for unskilled or semiskilled jobs, $31 \%$ for skilled labor and technical jobs, and $44 \%$ for professional jobs); however, for the remaining $21 \%$ of the sample, aspirations and expectations fell into different categories.

\section{Reciprocal Relations between Adolescent Future-Oriented Cognitions and Behavior}

Our second research question was whether future-oriented cognitions predicted subsequent adolescent activities, and vice versa. To provide a stringent test of these effects, we conducted regression analyses that controlled for the dependent variable at $\mathrm{T} 1$; thus a significant effect indicated that the predictor contributed to change in the dependent variable from T1 to T2. Because delinquency and volunteer activities were not correlated with future-oriented cognitions, they were not examined. Mother's education, gender, age, and GPA were included as controls. The first set of analyses regressed each activity (T2) onto future-oriented cognitions (T1), controls, and the activity at T1. Results regarding academic and extracurricular activities are provided in Tables 3 and 4 . All three future-oriented cognitions significantly predicted increases in academic activities (Table 3, Models 13), and occupational and educational expectations predicted increases in extracurricular activities (Table 4, Models 1-3). None of the future-oriented cognitions predicted changes in vocational activities or substance use over time ( $p s>.10$; results not shown). The second set of analyses regressed each future cognition (T2) onto activities (T1), controls, and the future cognition at T1 (not shown). Results indicated that neither academic nor vocational activities predicted change in future-oriented cognitions, $\beta(6,258)=.11$ and $\beta(6,258)=$ -.01 , respectively, $p \mathrm{~s}>.05$; however, extracurricular activities significantly predicted increases in occupational expectations, $\beta(6,252)=.18, p<.01$, and educational expectations, $\beta(6,252)=.11, p<.03$. Thus, evidence of bidirectional effects was found between both types of expectation and extracurricular activities.

\section{Predicting Young Adult Educational Attainment}

The remaining questions were whether future-oriented cognitions and activities in adolescence predicted young adult educational attainment and whether activities mediated these relations. In multiple regression analyses, we predicted adult educational attainment (T3) from controls (T1), each future cognition separately (T1), and adolescent activities (T2; see Table 5). In Model 1, occupational aspirations contributed significantly and positively to the model predicting young adult educational attainment (Step 2), and the coefficient did not decrease when potential behavioral mediators were added to the model (Step 3). In Model 2, occu- 


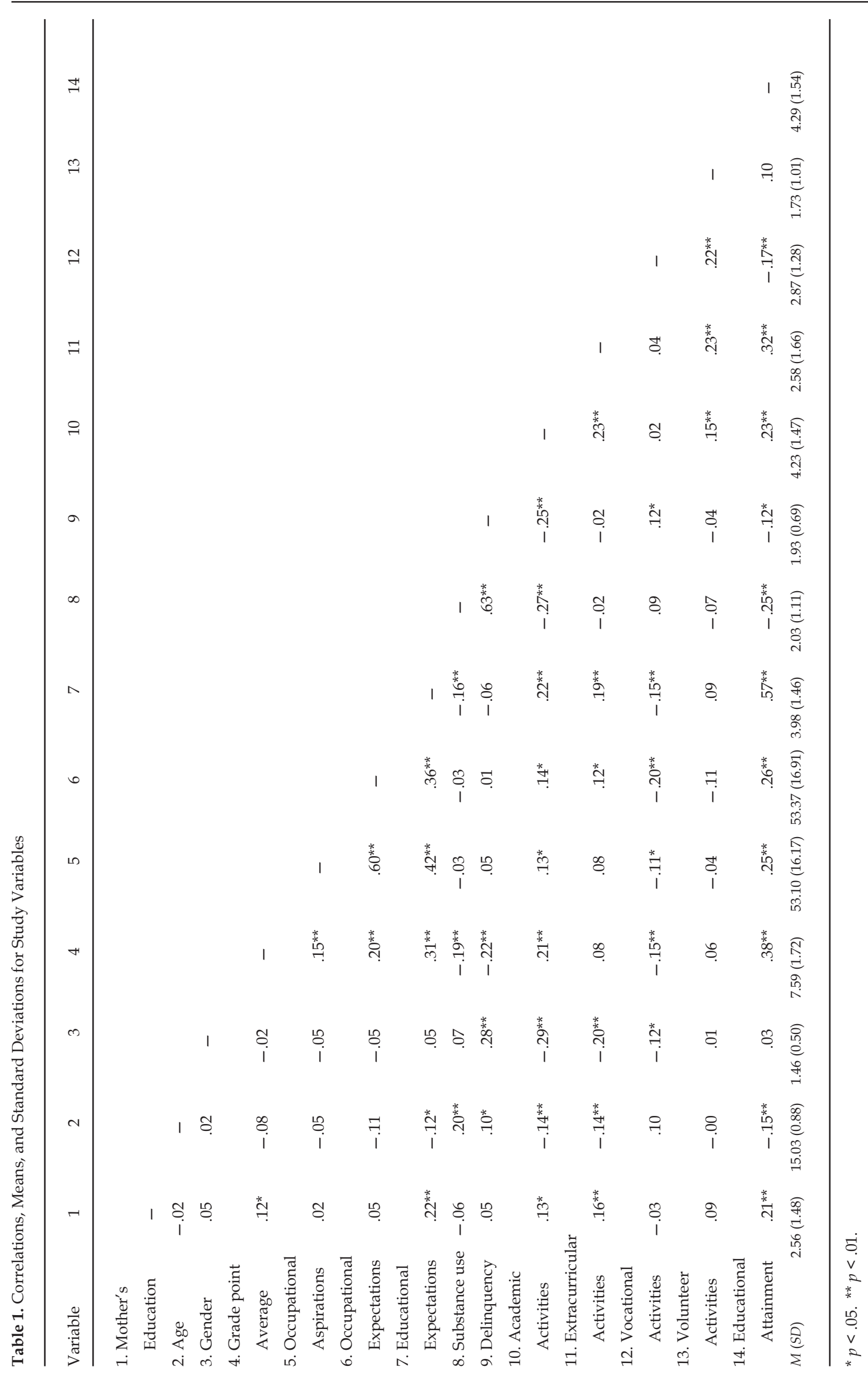


Table 2. Frequencies for Future-Oriented Cognitions at Time 1 (T1) and Time 2 (T2)

\begin{tabular}{lcccrrr}
\hline & \multicolumn{2}{c}{ Occupational aspirations } & \multicolumn{2}{c}{ Occupational expectations } & \multicolumn{2}{c}{ Educational expectations } \\
Group & $\mathrm{T} 1 n(\%)$ & $\mathrm{T} 2 n(\%)$ & $\mathrm{T} 1 n(\%)$ & $\mathrm{T} 2 n(\%)$ & $\mathrm{T} 1 n(\%)$ & $\mathrm{T} 2 n(\%)$ \\
\hline 1 & $15(5.15)$ & $8(2.75)$ & $18(6.57)$ & $17(6.20)$ & $122(40.13)$ & $94(30.92)$ \\
2 & $109(37.46)$ & $112(38.49)$ & $96(35.03)$ & $104(37.96)$ & $128(42.11)$ & $161(52.96)$ \\
3 & $167(57.39)$ & $171(58.76)$ & $160(58.39)$ & $153(55.84)$ & $54(17.76)$ & $49(16.11)$ \\
\hline
\end{tabular}

For occupational aspirations and expectations, groups were based on prestige scores: Group 1 = 0-30, Group 2 = 31-50, Group 3 $=51$ or more. For educational expectations, Group 1 = some high school to technical training, Group $2=$ some college to college degree, Group 3 = advanced degree.

pational expectations positively and significantly predicted young adult educational attainment in Step 2. Once adolescent behaviors were added to the equation (Step 3), the effect of extracurricular activities was significant, and the effect of occupational expectation was no longer significant. Finally, in Model 3, educational expectations positively predicted young adult educational attainment, and the effect was significant (Step 2). After adolescent behaviors were added (Step 3), the effect of extracurricular activities was significant; educational expectations continued to contribute significantly to the model, but the coefficient decreased.

Based on these results, the possible mediating role of extracurricular activities was explored. In the manner of Baron and Kenny (1986), educational attainment was regressed on occupational expectations $(\beta=.17, p<.01)$ and educational expectations $(\beta=.48, p<.01)$ in separate models with controls included. Extracurricular activities were regressed on occupational expectations $(\beta=.09, p<.05)$ and educational expectations $(\beta=.19, p<.01)$ separately, with controls in each model. Finally, educational attainment was regressed on extracurricular activities and each expectation separately, along with controls $(\beta=.26, p<.01$, for occupational and $\beta$ $=.20, p<.01$, for educational expectations, respectively). Sobel tests indicated that extracurricular activities fully mediated the effect of occupational expectations $(z=4.33, p<.01)$ and partially mediated the effect of educational expectations $(z=2.40, p=.01)$. We repeated the regressions predicting educational attainment, substituting T1 measures of activities for T2 measures. The only difference was that extracurricular activities partially (rather than fully) mediated the association between occupational expectations and educational attainment.

\section{Discussion}

Adolescents' future cognitions are thought to play an influential role in their subsequent development. To illuminate this possible connection, the present study explored developmental changes in adolescents' future-oriented cognitions; examined the relations among these cognitions, adolescents' activities, and adult educational attainment; and tested the possibility that adolescent behaviors (activities) might mediate these relations. Results indicated that adolescents' aspirations and expectations predicted adult educational attainment 8 years later, attesting to the importance of future-oriented cognitions for later development. Adolescents' extracurricular activities partially mediated the impact of occupational and educational expectations on educational attainment, suggesting that expectations operate in part by motivating relevant behaviors.

The finding that extracurricular activities partially mediated the association between expectations and adult educational attainment is consistent with the theoretical notion that future-oriented cognitions motivate behavior (e.g., Markus \& Nurius, 1986). It also extends the growing literature on the role of extracurricular activities in adolescents' identity development and future outcomes (Eccles et al., 2003) and is consistent with empirical research documenting a connection between adolescents' behaviors and their subsequent attainment (e.g., Troutman \& Dufur, 2007). Other adolescent behaviors (vocational, volunteer, delinquency) did not serve as mediators. Adolescents often view vocational activities (e.g., part-time jobs) as a way to earn discretionary income rather than as paths to future occupations (e.g., Bachman, Safron, Sy, \& Schulenberg, 2003). Similarly, youth may

Table 3. Regressions Predicting Academic Activities from Future-Oriented Cognitions at Time 1

\begin{tabular}{lccc}
\hline Predictor & Model 1 & Model 2 & Model 3 \\
\hline Academic activities & $.38^{* *}$ & $.39^{* *}$ & $.39^{* *}$ \\
Mother's education & .05 & .08 & .02 \\
Age & .01 & .01 & -.01 \\
Gender & -.10 & -.11 & $.12^{*}$ \\
Grade point average & $.20^{* *}$ & $.17^{* *}$ & $.14^{* *}$ \\
Occupational aspirations & $.12^{*}$ & $.09^{*}$ & .31 \\
Occupational expectations & & & .29 \\
Educational expectations & & & \\
$R^{2}$ & .30 & &
\end{tabular}

Main entries are standardized coefficients. $N=292-302$.

${ }^{*} p<.05 .{ }^{* *} p<.01$. 
Table 4. Regressions Predicting Extracurricular Activities from Future-Oriented Cognitions at Time 1

\begin{tabular}{lccc}
\hline Predictor & Model 1 & Model 2 & Model 3 \\
\hline Extracurricular activities & $.45^{* *}$ & $.44^{* *}$ & $.42^{* *}$ \\
Mother's education & .08 & .09 & .08 \\
Age & $.11^{*}$ & $.11^{*}$ & $.11^{*}$ \\
Gender & $-.15^{*}$ & $-.15^{* *}$ & $-.18^{* *}$ \\
Grade point average & .07 & .03 & .01 \\
Occupational aspirations & -.06 & $.08^{*}$ & $.12^{*}$ \\
Occupational expectations & & & .30 \\
Educational expectations & .29 & .29 & \\
$R^{2}$ & &
\end{tabular}

Main entries are standardized coefficients. $N=274-284$.

${ }^{*} p<.05 .{ }^{* *} p<.01$.

receive benefits from volunteering (e.g., self-esteem) that are not related to their occupational goals (Schondel \& Boehm, 2000). Although a connection between delinquency and future-oriented cognitions has been reported (Oyserman \& Markus, 1990), that study was conducted with incarcerated youth, whereas the present sample had relatively low levels of delinquency and substance use. Perhaps any connection between these negative activities and future-oriented cognitions is attenuated in a community sample such as ours.

A second issue concerned the distinction between aspirations and expectations. The distinction was reflected in the correlation between occupational aspirations and expectations, which was .60, indicating only $36 \%$ shared variance. When scores were collapsed into broad occupational categories based on skill level, the correspondence between aspirations and expectations was greater, suggesting that most youth reported aspirations and expectations that required similar levels of skill and training, despite discrepancies in job type and occupational prestige. Nonetheless, $21 \%$ of youth reported aspirations and expectations from different skill categories. This indicates that aspirations and expectations are distinct, as suggested by some theorists (Gottfredson, 1981; Markus \& Nurius, 1986).

In theory, self-cognitions motivate behavior but could also be adjusted based on feedback from behavior, and some prior empirical research supports this latter effect (Eccles et al., 2003; Oyserman \& Markus, 1990). Our tests of reciprocal effects indicated that aspirations predicted change in academic activities but not the reverse, consistent with a unidirectional effect. In contrast, the relations between educational and occupational expectations and extracurricular activities were bidirectional. This suggests that expectations are sensitive to feedback from experience (i.e., extracurricular activities) but aspirations are not. Moreover, the effect of occupational aspirations on educational attainment was not mediated by any of the behaviors studied. Apparently,

Table 5. Regressions Predicting Educational Attainment from Adolescents' Future-Oriented Cognitions, Activities, and Controls

\begin{tabular}{|c|c|c|c|c|c|c|c|c|c|}
\hline \multirow[b]{2}{*}{ Predictor } & \multicolumn{3}{|c|}{ Model $1^{\mathrm{a}}$} & \multicolumn{3}{|c|}{ Model $2^{b}$} & \multicolumn{3}{|c|}{ Model $3^{c}$} \\
\hline & Step 1 & Step 2 & Step 3 & Step 1 & Step 2 & Step 3 & Step 1 & Step 2 & Step 3 \\
\hline Mother's education & $.22 * *$ & $.22 * *$ & $.16^{* *}$ & $.24^{* *}$ & $.23^{* *}$ & $.17^{* *}$ & $.27^{* *}$ & $.19^{* *}$ & $.16^{* *}$ \\
\hline Age & .04 & .04 & .04 & .03 & .04 & .04 & .01 & .02 & .01 \\
\hline Gender & .03 & .04 & $.11^{*}$ & .05 & .06 & $.14^{* *}$ & .05 & .03 & .09 \\
\hline Grade point average & $.40^{* *}$ & $.38 * *$ & $.34^{* *}$ & $.42^{* *}$ & $.39 * *$ & $.34^{* *}$ & $.37^{* *}$ & $.25^{* *}$ & $.23^{* *}$ \\
\hline Occupational aspirations & & $.12^{*}$ & $.12^{*}$ & & & & & & \\
\hline Occupational expectations & & & & & $.11^{*}$ & .08 & & & \\
\hline Educational expectations & & & & & & & & $.39 * *$ & $.35^{*}$ \\
\hline Delinquency (T2) & & & -.05 & & & .08 & & & .08 \\
\hline Academic activities (T2) & & & .04 & & & .11 & & & .03 \\
\hline Extracurricular activities (T2) & & & $.23 * *$ & & & $.20 * *$ & & & $.15^{* *}$ \\
\hline Vocational activities (T2) & & & -.05 & & & -.07 & & & -.04 \\
\hline Volunteer activities (T2) & & & .01 & & & -.01 & & & -.03 \\
\hline$R^{2}$ & .22 & .24 & .30 & .24 & .25 & .32 & .23 & .35 & .38 \\
\hline$\Delta R^{2}$ & & .01 & .06 & & .01 & .07 & & .13 & .03 \\
\hline$\Delta F$ & $20.13^{* *}$ & $5.18^{*}$ & $4.57^{* *}$ & $21.86^{* *}$ & $4.48^{*}$ & $5.47^{* *}$ & $20.79 * *$ & $56.19 * *$ & $2.55^{*}$ \\
\hline$N$ & & 285 & & & 280 & & & 291 & \\
\hline
\end{tabular}

Table entries are standardized regression coefficients. T2 = Time 2.

a Model 1: occupational aspirations (Time 1 [T1]) predicting educational attainment (Time 3 [T3]). ${ }^{b}$ Model 2: occupational expectations (T1) predicting educational attainment (T3). ${ }^{\mathrm{c}}$ Model 3: educational expectations (T1) predicting educational attainment (T3).

${ }^{*} p<.05 .{ }^{* *} p<.01$. 
the effects of aspirations do not operate through behaviors (at least those assessed in this study) but through some other process. Gottfredson (1981) has suggested that aspirations are less realistic than expectations. If so, behaviors would be less likely to shape adolescents' aspirations, consistent with the present results. Further, aspirations and expectations appear to operate through somewhat different pathways. Whereas expectations and behavior may affect each other in a gradual recursive process, aspirations appear less tied to behavioral experience and feedback. This distinction merits additional theoretical and empirical attention. It is also possible that other variables, such as personality, underlie future-oriented cognitions, choice of activities, and later life outcomes (Little, 2007).

Future-oriented cognitions showed moderate stability over a 1-year period. This suggests that although some adolescents maintain their aspirations and expectations for the future, for others, future-oriented cognitions are in flux. Perhaps these latter adolescents are still exploring their options and have not yet settled on specific goals. In future studies, it would be useful to determine the characteristics of this group of adolescents and follow them over time to learn how this inconsistency affects their transition to adulthood, for example, by delaying or altering adult attainments.

As with all exploratory research, the present results need to be replicated in future studies. Additionally, the current findings must be viewed in light of several limitations. The data came from a sample of primarily White rural adolescents, and generalizability to other populations may be limited. In future studies it may be useful to explore the impact of future-oriented cognitions in urban samples and other ethnic groups, in which the linkages between future-oriented cognitions and specific activities may vary. Additionally, the measures in this study assessed only two domains of futureoriented cognitions (occupation and education). Often measures of future-oriented cognitions, especially those assessing possible selves, are more open-ended and capture a broader range of future states. Finally, the present study focused on adult educational attainment. Future studies should examine other adult outcomes and investigate the role of other behaviors as potential mediators.

Despite these limitations, the present study makes several contributions to the literature on the development and effects of adolescents' future-oriented cognitions. The results highlight the importance of future-oriented cognitions for adolescents' behaviors and ultimately their adult educational attainment. This supports the theoretical notion that future-oriented cognitions affect behavior and play an influential role in shaping life trajectories (e.g., Little, 2007; Markus \& Nurius, 1986; Nurmi, 2004). Equally important, the results yield insight into the processes through which this may occur, such as the bidirectional interplay between expectations and participation in extracurricular activities. The reciprocal relations between expectations and behaviors indicate that adolescents are capable of adjusting their future expectations based on feedback via their experiences (Eccles et al., 2003). That the effects of expectations were mediated (at least partially) by behavior suggests that adolescents can use their projections about the future to inform their behaviors in ways that promote later achievement. Finally, the fact that the effect of occupational aspirations was not mediated by any of the behaviors examined suggests that some future- oriented cognitions may operate in ways other than goal-directed behavior, pointing to a potentially important difference between aspirations and expectations. Taken together, these findings provide evidence of the significance of adolescents' cognitions about the future, showing that what adolescents think about their futures is relevant for their development in adolescence and adulthood.

\section{References}

Armstrong, P., \& Crombie, G. (2000). Compromises in adolescents' occupational aspirations and expectations from Grades 8 to 10. Journal of Vocational Behavior, 56(1), 82-98.

Bachman, J. G., Safron, D. J., Sy, S. R., \& Schulenberg, J. E. (2003). Wishing to work: New perspectives on how adolescents' part-time work intensity is linked to educational disengagement, substance use, and other problem behaviours. International Journal of Behavioral Development, 27(4), 301-315.

Baron, R. M., \& Kenny, D. A. (1986). The moderator-mediator variable distinction in social psychological research: Conceptual, strategic, and statistical considerations. Journal of Personality and Social Psychology, 51, 1173-1182.

Blakemore, S. -J., \& Choudhury, S. (2006). Development of the adolescent brain: Implications for executive function and social cognition. Journal of Child Psychology and Psychiatry, 47, 296-312.

Cantor, N. (1990). From thought to behavior: "Having" and "doing" in the study of personality and cognition. American Psychologist, 45, 735-750.

Crockett, L. J., \& Bingham, C. R. (2000). Anticipating adulthood: Expected timing of work and family transitions among rural youth. Journal of Research on Adolescence, 10, 151-172.

Eccles, J., \& Barber, B. (1999). Student council, volunteering, basketball, or marching band: What kind of extracurricular involvement matters? Journal of Adolescent Research, 14(1), 10-43.

Eccles, J., Barber, B., Stone, M., \& Hunt, J. (2003). Extracurricular activities and adolescent development. Journal of Social Issues, 59, 865-889.

Erikson, E. H. (1968). Identity: Youth and crisis. New York, NY: Norton.

Gottfredson, L. S. (1981). Circumscription and compromise: A developmental theory of occupational aspirations. Journal of Counseling Psychology, 28(6), 545-579.

King, K., Meehan, B., Trim, R., \& Chassin, L. (2006). Marker or mediator? The effects of adolescent substance use on young adult educational attainment. Addiction, 101(12), 1730-1740.

Little, B. R. (2007). Prompt and circumstance: The generative contexts of personal projects analysis. In B.Little, K.Salmela-Aro, \& S.Phillips (Eds.), Personal project pursuit: Goals, actions, and human flourishing (pp. 3-49). Mahwah, NJ: Erlbaum.

Markus, H., \& Nurius, P. (1986). Possible selves. American Psychologist, 41, 954-969.

Messersmith, E. E., \& Schulenberg, J. E. (2008). When can we expect the unexpected? Predicting educational attainment when it differs from previous expectations. Journal of Social Issues, 64(1), 195-211. 
Nurmi, J. -E. (1989). Development of orientation to the future during early adolescence: A four-year longitudinal study and two cross-sectional comparisons. International Journal of Psychology, 24, 195-214.

Nurmi, J. -E. (1991). How do adolescents see their future? A review of the development of future orientation and planning. Developmental Review, 11, 1-59.

Nurmi, J. -E. (2004). Socialization and self-development: Channeling, selection, adjustment, and reflection. In R.Lerner \& L.Steinberg (Eds.). Handbook of adolescent psychology (2nd ed., pp. 85-124). Hoboken, NJ: Wiley.

Ou, S. -R., \& Reynolds, A. J. (2008). Predictors of educational attainment in the Chicago Longitudinal Study. School Psychology Quarterly, 23(2), 199-229.
Oyserman, D., \& Markus, H. R. (1990). Possible selves and delinquency. Journal of Personality and Social Psychology, 59, 112-125.

Schondel, C. K., \& Boehm, K. E. (2000). Motivational needs of adolescent volunteers. Adolescence, 35, 335-344.

Swisher, J. D., Shute, R. E., \& Bibeau, D. (1984). Assessing drug and alcohol abuse: An instrument for planning and evaluation. Measurement and Evaluation in Counseling and Development, 7(2), 91-97.

Troutman, K. P., \& Dufur, M. J. (2007). From high school jocks to college grads: Assessing the long-term effects of school sports participation on females' educational attainment. Youth E Society, 38(4), 443-462. 